\title{
Anterograde irrigation - assisted ureteroscopic lithotripsy in patients with percutaneous nephrostomy
}

\author{
Jemo Yoo ${ }^{1}$, Seung-Ju Lee ${ }^{1}$, Hyun-Sop Choe ${ }^{1}$, Hee Youn Kim ${ }^{1}$, Joon Ho Lee ${ }^{1}$, Dong Sup Lee ${ }^{1}$ \\ ${ }^{1}$ St. Vincent's Hospital, College of Medicine, The Catholic University of Korea
}

\begin{abstract}
In complicated urinary tract infection with ureteral calculi, urinary diversion is inevitable. So, stenting or percutaneous drainage can be an option. In hemodynamically unstable patients, percutaneous drainage is superior to ureteral stenting (1). Once acute infection is controlled, definite treatment of the stone is necessary. According to a guideline, semirigid ureteroscopy is recommended for lower and mid - ureter stone and flexible ureteroscopy for upper ureter stone (2). Semi - rigid ureteroscopy can migrate stone to kidney, especially in upper ureter stone, lowering stone free rate (3). Not only flexible ureteroscopy creates additional costs but also is barely available in developing countries $(4,5)$. So, the authors would like to introduce anterograde irrigation - assisted ureteroscopic lithotripsy in patients with percutaneous nephrostomy.

Retrograde irrigation was connected and flowed minimally enough to secure visual field. Once stone is noted, another saline irrigation, which is placed above $40 \mathrm{~cm}$ over the patient is connected to nephrostomy. Retrograde irrigation is disconnected from ureteroscope and the previous connected channel on ureteroscope is opened. Actual pressure detected by barometer from the opened channel of ureteroscope is usually about $30 \mathrm{cmH}_{2} \mathrm{O}$ while anterograde irrigation is administered in maximal flow, which means fully opened anterograde irrigation is not hazardous to kidney. There was no complication in 17 patients submitted to this method.

Video shows advantages of our practice: clear visual field; reduced risk of stone migration into kidney; induced spontaneous passage of fragments without using instrumentation; and decreased operation time. In short, most of surgeons, even unexperienced, can perform an excellent procedure with less time consuming using our method.
\end{abstract}

\section{CONFLICT OF INTEREST}

None declared.

\section{ARTICLE INFO}

Available at: http://www.intbrazjurol.com.br/video-section/20180238_Yoo_et_al Int Braz J Urol. 2019; 45 (Video \#5): 406-7
Submitted for publication:

April 02, 2018

Accepted after revision: July 09, 2018

Published as Ahead of Print: August 10, 2018 


\section{REFERENCES}

1. Mokhmalji H, Braun PM, Martinez Portillo FJ, Siegsmund M, Alken P, Köhrmann KU. Percutaneous nephrostomy versus ureteral stents for diversion of hydronephrosis caused by stones: a prospective, randomized clinical trial. J Urol. 2001;165:1088-92.

2. Hyams ES, Monga M, Pearle MS, Antonelli JA, Semins MJ, Assimos DG, et al. A prospective, multi-institutional study of flexible ureteroscopy for proximal ureteral stones smaller than $2 \mathrm{~cm}$. J Urol. 2015;193:165-9.

3. Assimos D, Krambeck A, Miller NL, Monga M, Murad MH, Nelson CP, et al. Surgical Management of Stones: American Urological Association / Endourological Society Guideline, PART I. J Urol. 2016;196:1153-60.

4. Wang Q, Guo J, Hu H, Lu Y, Zhang J, Qin B, et al. Rigid ureteroscopic lithotripsy versus percutaneous nephrolithotomy for large proximal ureteral stones: A meta analysis. PLoS One. 2017;12:e0171478.

5. Proietti S, Dragos L, Molina W, Doizi S, Giusti G, Traxer 0. Comparison of New Single-Use Digital Flexible Ureteroscope Versus Nondisposable Fiber Optic and Digital Ureteroscope in a Cadaveric Model. J Endourol. 2016;30:655-9.

Correspondence address: Dong Sup Lee, MD, PhD St. Vincent's Hospital College of medicine The Catholic University of Korea 93 -6 Ji - dong Paldal - gu, Suwon 442 723, 16247, South Korea Fax: +82 31 253-0949 E-mail: lds@catholic.ac.kr 